\title{
CORRIGENDUM
}

\section{Correction: Guidelines for the prevention, detection and management of the renal complications of COVID- 19 in Africa}

\begin{abstract}
Hesham M Elsayed ${ }^{* 1}$, Shoyab Wadee*2, Mohamed S Zaki*3, Anthony JO Were ${ }^{4}$, Gloria E Ashuntantang ${ }^{5}$, Ebun L Bamgboye , Mogamat Razeen Davids ${ }^{7}$, Mohamed H Hafez ${ }^{8}$, Maimouna Mahamat ${ }^{5}$, Saraladevi Naicker ${ }^{9}$, Abdou Niang ${ }^{10}$, Sidy M Seck ${ }^{1 !}$, Charles R Swanepoel'2, Elliot KTannor'3, Ahmed Twahir ${ }^{14}$, K Hubert Yao ${ }^{15}$

'Departments of Internal Medicine and Nephrology, Ain Shams Medical University, Cairo, Egypt; ${ }^{2}$ Wits Donald Gordon Medical Centre, University of the Witwatersrand, Johannesburg, South Africa; ${ }^{N}$ Nephrology Department, National Institute of Urology and Nephrology, Cairo, Egypt; ${ }^{~}$ East African Kidney Institute, and Department of Medicine, College of Health Sciences, University of Nairobi, Kenya; ${ }^{5}$ Department of Internal Medicine, Yaoundé General Hospital and University of Yaoundé I, Cameroon; ' ${ }^{S}$ t Nicholas Hospital, Lagos, Nigeria; ' Division of Nephrology, Stellenbosch University and Tygerberg Hospital, Cape Town, South Africa; ${ }^{8}$ Nephrology Department, Faculty of Medicine, Cairo University, Cairo, Egypt; ${ }^{9}$ Department of Internal Medicine, School of Clinical Medicine, University of the Witwatersrand, Johannesburg, South Africa; ' ${ }^{\circ}$ Department of Nephrology, Cheikh Anta Diop University, Dakar, Senegal; "Departments of Internal Medicine and Nephrology, Faculty of Health Sciences, Gaston Berger University, Saint-Louis, Senegal; '2Division of Nephrology, Department of Medicine, University of Cape Town, South Africa; ${ }^{3}$ Renal Unit, Department of Medicine, Komfo Anokye Teaching Hospital, Kumasi, Ghana; ${ }^{14}$ Parklands Kidney Centre and Aga Khan University Hospital, Nairobi, Kenya; ${ }^{5}$ University Hospital of Treichville, Felix Houphouet-Boigny University, Abidjan, Côte d'Ivoire.
\end{abstract}

The authors of the article 'Guidelines for the prevention, detection and management of the renal complications of COVID-19 in Africa' [I] wish to acknowledge the contribution of Professor Hussein El Fishawy. Our guidelines drew on various sources, including the Egyptian Ministry of Health guidelines, portions of which were adapted and reproduced with permission from the Egyptian Ministry of Health. Two of the authors of those guidelines, Professors Elsayed and Zaki, are also coauthors of our paper. Professor El Fishawy was the third author of the Egyptian guidelines and we would like to acknowledge his contribution to our review through this source, especially with respect to the treatment algorithms for patients with kidney transplants and those with acute kidney injury.

\section{REFERENCE}

\footnotetext{
I. Elsayed HM, Wadee S, Zaki MS, Were AJO, Ashuntantang GE, Bamgboye EL, et al. Guidelines for the prevention, detection and management of the renal complications of COVID-19 in Africa. Afr J Nephrol. 2020; 23(1):109-126.
}

Received 23 June 2020; published 09 July 2020. 